\title{
A Study on Salt Damage Pollution Forecasting by Measuring Leakage Current
}

\author{
Dae-Dong Lee* ${ }^{*}$ Dong-Seok Hyun - Young-Dal Kim
}

\begin{abstract}
Faults due to salt damage prevent the provision of stable power supply because they affect large areas and require much time and man power for recovery. Korea, three sides of which are surrounded by sea, is especially exposed to the impact of sea winds and typhoons. Therefore, salt damage to power facilities is one of the greatest problems of Korea's power system. To prevent salt damage pollution of insulators, the salt damage deposit on the insulators is regularly measured, and the insulators are washed when their salt damage deposits are expected to reach a critical level. When salt is detected on the insulators, however, errors are likely to occur according to different workers and environments. Therefore, a leakage current measurement method was proposed in this study to check the salt damage pollution level and reduce these errors.
\end{abstract}

Key Words : Salt Damage Pollution, Suspension Insulator, Leakage Current Measurement

\section{Introduction}

Salt and dust deposits on insulators result in faults, but measures to prevent them are at the primary level. Korea Electric Power Corporation (KEPCO) regularly washes its insulators to prevent faults due to salt and dust, but this is not enough to effectively diagnose and prevent faults caused by typhoons and rapid dust pollution.

If salt from typhoons or dust from plant areas are

\footnotetext{
* Main author : Ph.D. Course in Electrical Engineering, Graduate School of Hanyang University
}

Tel : +82-42-821-1089, Fax : +82-42-821-1088

E-mail : ldd77@hanbat.ac.kr

Date of submit:2010. 5. 13

First assessment : 2010. 5. 20

Completion of assessment : 2010. 6. 9 deposited on transmission lines, they may trip simultaneously and lead to large- ${ }^{-}$scale power outages. Examples of this are the faults that occurred in and out of Korea, including those on the west coast (1993) and in Ulsan (2003). These faults in directly prove that defects caused by rapid salt and dust pollution can greatly affect the economy and industry [1].

In Korea, the technical level of insulator maintenance is relatively low, and there is no forecast technology or monitoring system for rapid pollution. Consequently, maintenance is performed regardless of the pollution condition of power facilities which leads to the waste of many resources.

Previous studies on this type of pollution were 
mainly passive. The electric characteristics of insulators and power facilities were evaluated according to their pollution condition, and the pollution level was determined based on the statistical approach of the long-term pollution level measurements. In Korea, the automatic pollution level measuring device has been imported and independently applied to the field, but the trial technology is not being used due to economic and maintenance problems.

The automatic contamination measurement method that was used in this study requires many resources for initial development and facilities construction, but it overcomes the time and manpower limits of manual pollution measurement. The measurement can be conducted daily which would enable the observation of rapid pollution and the consistent pollution measurement of outdoor insulators. Therefore, the automatic pollution measurement method must be used to measure and monitor rapid pollution due to climatic changes.

\section{Leakage Current According to Humidity}

\subsection{Experimental Method and Conditions}

To determine the relationship between humidity and the leakage current, changes in the leakage current according to temperature and humidity, which are the most important factors of insulator pollution, were measured. By controlling temperature and humidity using a thermo-hydrostat program control, the factor with the closest relationship to the leakage current was found when the applied voltage, humidity, and temperature were changed.
The temperature was set at $10\left[{ }^{\circ} \mathrm{C}\right], 25\left[{ }^{\circ} \mathrm{C}\right]$ and 35 $\left[{ }^{\circ} \mathrm{C}\right]$, and the humidity ranged from $30[\%]$ to $90[\%]$. The temperature and humidity were controlled using the thermo-hydrostat program control. The measurements were taken for 8-10 hours.

A high-voltage line was simulated using $220[\mathrm{~V}]$ of power (VS) and a step-up pole transformer (T1) to boost the voltage to $10[\mathrm{kV}]$. The high voltage was stepped down to the voltage that customers use, $200[\mathrm{~V}]$, using a step-down pole transformer (T2).

A load (L) was connected to the step-down voltage terminal as the customer load. One wire was tapped from the high-voltage line to a suspension insulator as the insulator of the transmission line. A $180[\mathrm{~mm}]$ Class 1 clevis-type suspension insulator (KSC 3821) was used. Fig. 1 shows the suspension insulator and Table 1 shows configuration and matter [2].

The suspension insulator was installed in the thermo-hydrostat that was used to control the temperature and humidity, the factors that significantly influence outdoor insulators. A voltage regulator (VR) was used to supply constant voltage from the power supply, and a molded case circuit breaker (MCCB) was installed to protect the power supply.

A $22.9[\mathrm{kV}] \mathrm{CNCV} 60\left[\mathrm{~mm}^{2}\right]$ power cable was used for the high-voltage line between the pole transformers. A current measurement clamp was installed to measure the current in the high-voltage line, and a current probe was installed on the low-voltage side to ensure safety and precise measurement and to measure the current in real time. A resistor was used on the ground side of the insulator to measure the leakage current of the insulator [3].

High-voltage, current, and leakage current data were acquired via a four-channel oscilloscope, and were stored in a PC. The system was formed so 
that the temperature and humidity data of the thermo hydrostat would also be stored in the PC in real time. Fig 2 shows the conceptual diagram of the equipment for measuring the leakage current due to salt damage pollution.

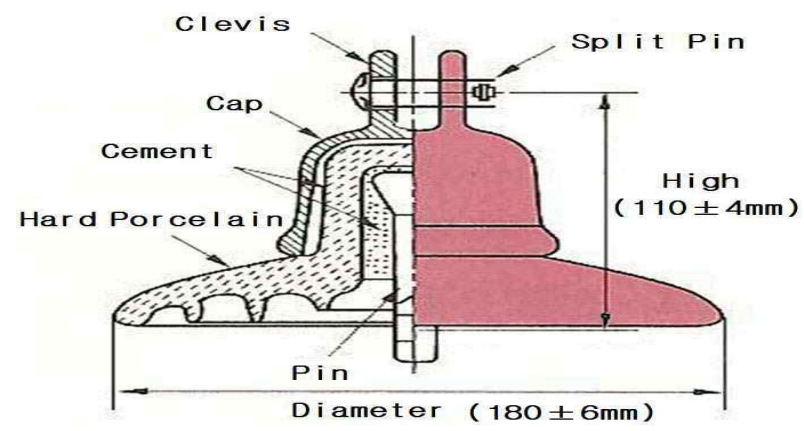

Fig. 1. $180[\mathrm{~mm}]$ Clevis-Type Suspension Insulator

Table 1. Configuration and Matter of Suspension Insulator

\begin{tabular}{|c|l|}
\hline Configuration & \multicolumn{1}{|c|}{ Matter } \\
\hline \multirow{3}{*}{ Cap } & - Tensile Strength : $32\left[\mathrm{kgf} / \mathrm{mm}^{2}\right]$ \\
& - Proof Stress : $19\left[\mathrm{kgf} / \mathrm{mm}^{2}\right]$ \\
& - Elongation : 8[\%] \\
\hline \multirow{3}{*}{ Bolt, Nut } & Steel-Structure (hot dip galvanizing) \\
& - Tensile Strength : 41[kgf $\left./ \mathrm{mm}^{2}\right]$ \\
& - Proof Stress : 25[kgf $\left./ \mathrm{mm}^{2}\right]$ \\
& - Elongation : 8[\%] \\
\hline Split Pin & Stainless Steel \\
\hline Cement & Portland Cement \\
\hline
\end{tabular}

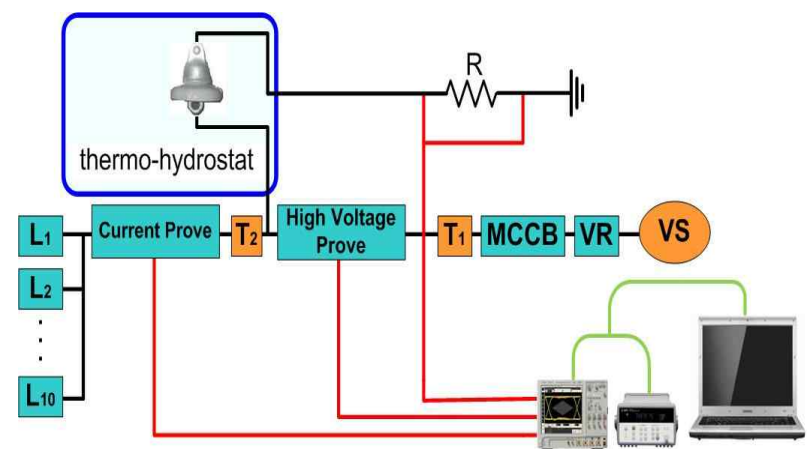

Fig. 2. Diagram of the Equipment for Measuring the Leakage Current due to Salt Damage Pollution

\subsection{Low-Voltage Side Current Measured According to Humidity}

In Figs. 3 and 4, which show the current values at $25\left[{ }^{\circ} \mathrm{C}\right]$ and $35\left[{ }^{\circ} \mathrm{C}\right]$, respectively, there is a slight increase in humidity with the increase in temperature. The current curves at $25\left[{ }^{\circ} \mathrm{C}\right]$ and $35\left[{ }^{\circ} \mathrm{C}\right]$ have nothing to do with the humidity.

In Fig. 5, which shows the change in the current according to the applied voltage, there is a change in the current according to the change in the voltage, but it seems to have nothing to do with the humidity, considering the results shown in Figs. 3 and 4.

Therefore, the temperature and humidity around the insulator have no proportional relationship to the voltage and current and have nothing to do with the pollution level measurement.

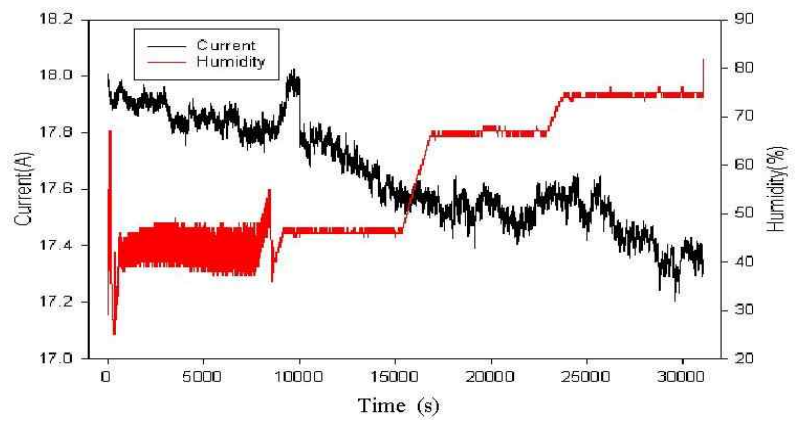

Fig. 3. Change in the Current at $25\left[{ }^{\circ} \mathrm{C}\right]$ According to Humidity

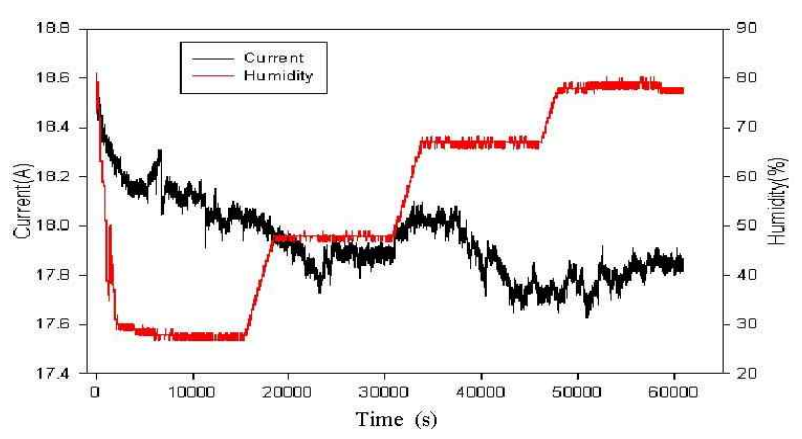

Fig. 4. Change in the Current at $35\left[{ }^{\circ} \mathrm{C}\right]$ According to Humidity 


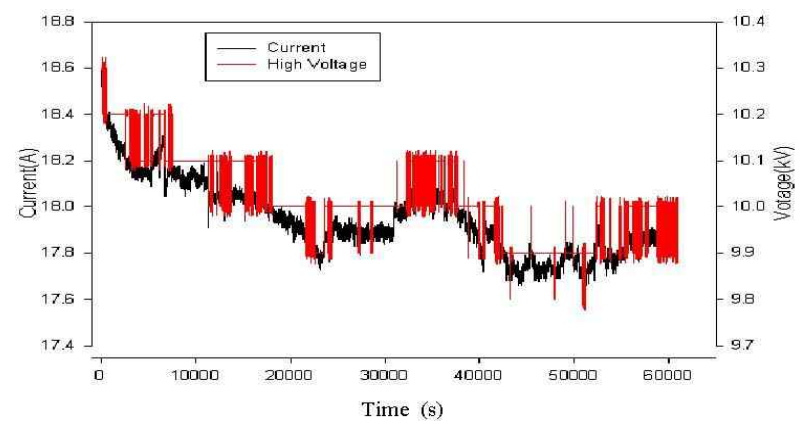

Fig. 5. Change in the Current at $35\left[{ }^{\circ} \mathrm{C}\right]$ According to the Applied Voltage

\subsection{Current Measured According to the Temperature and Applied Voltage at a Constant Humidity}

Figs. 6 and 7 show the current measurement results when the temperature remains at a constant humidity. In Fig. 6, with a relative humidity of $50[\%]$, the temperature was controlled at $10\left[{ }^{\circ} \mathrm{C}\right], 20$ $\left[{ }^{\circ} \mathrm{C}\right], 25\left[{ }^{\circ} \mathrm{C}\right]$, and $35\left[{ }^{\circ} \mathrm{C}\right]$. In Fig. 7 , with a relative humidity of $70[\%]$, the temperature was controlled at $20\left[{ }^{\circ} \mathrm{C}\right], 25\left[{ }^{\circ} \mathrm{C}\right]$, and $35\left[{ }^{\circ} \mathrm{C}\right]$. In the common temperature conditions, $20\left[{ }^{\circ} \mathrm{C}\right], 25\left[{ }^{\circ} \mathrm{C}\right]$, and $35\left[{ }^{\circ} \mathrm{C}\right]$, no proportional relationship was found between the temperature and the current.

Therefore, it seems that the current value of the change in temperature at a constant humidity cannot be an index of the pollution level.

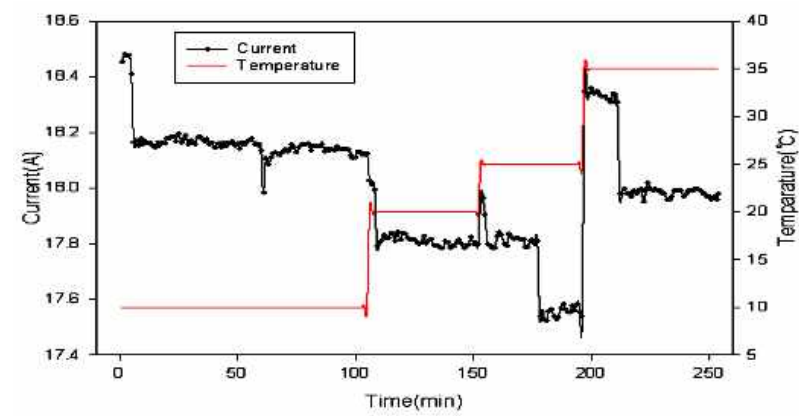

Fig. 6. Current According to Temperature at $50[\%] \mathrm{RH}$

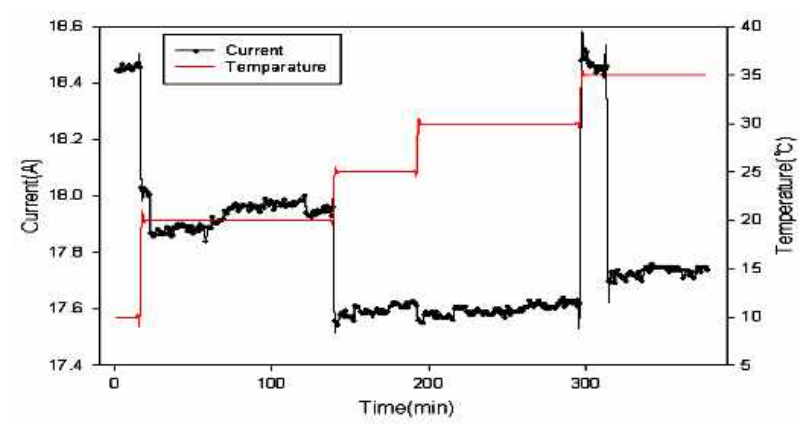

Fig. 7. Current According to Temperature at 70[\%] $\mathrm{RH}$

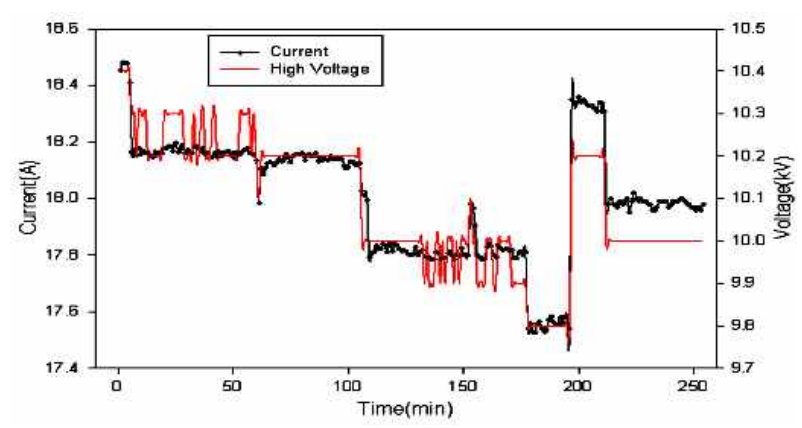

Fig. 8. Current According to Applied Voltage at $50[\%] \mathrm{RH}$

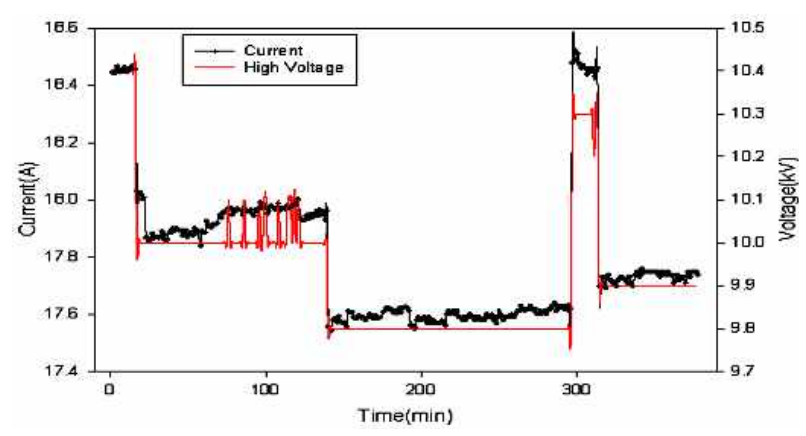

Fig. 9. Current According to Applied Voltage at 70[\%] $\mathrm{RH}$

Figs. 8 and 9 show the current at a constant humidity when the relative humidity was 50[\%] and $70[\%]$, respectively. They show the change in the current with the change in the voltage.

The current was proportional only to the applied voltage. The change in the current in the cases with the $50[\%]$ and $70[\%]$ relative humidity were not 
attributed to the humidity, but only to the change in the applied voltage. Therefore, it was found that the current is proportional to the applied voltage but has nothing to do with the humidity.

\subsection{Leakage Current Measured According to the Humidity and Applied Voltage at a Constant Temperature}

Figs. 10, 11, and 12 show the leakage current according to the humidity at a constant temperature.

The humidity condition was 30-70[\%]. The leakage current hardly changed at a low humidity, but it rapidly increased after the relative humidity exceeded 50[\%] [20,000-30,000[s] in Fig. 10 and 20,000-25,000[s] in Fig. 11].

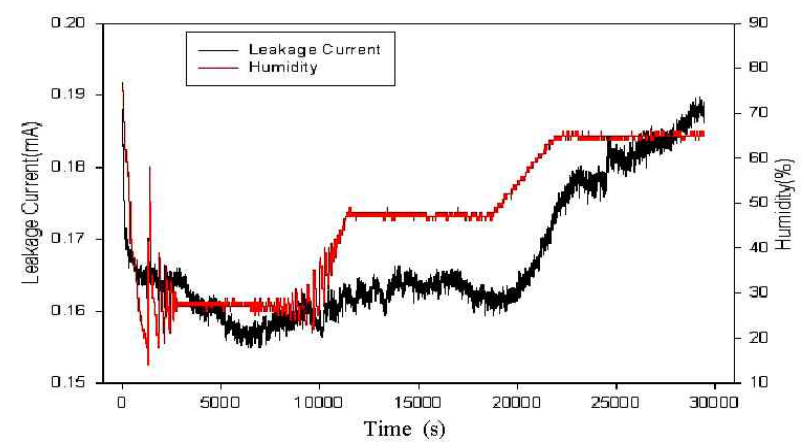

Fig. 10. Change in the Leakage Current According to Humidity at $10\left[^{\circ} \mathrm{C}\right]$

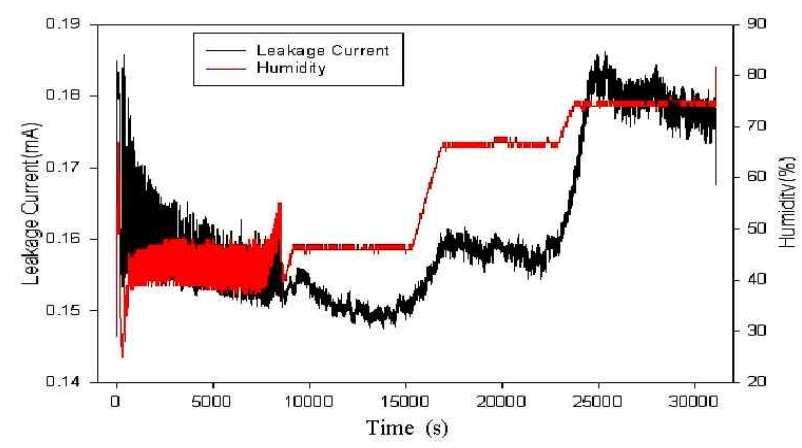

Fig. 11. Change in Leakage Current According to Humidity at $25\left[{ }^{\circ} \mathrm{C}\right]$

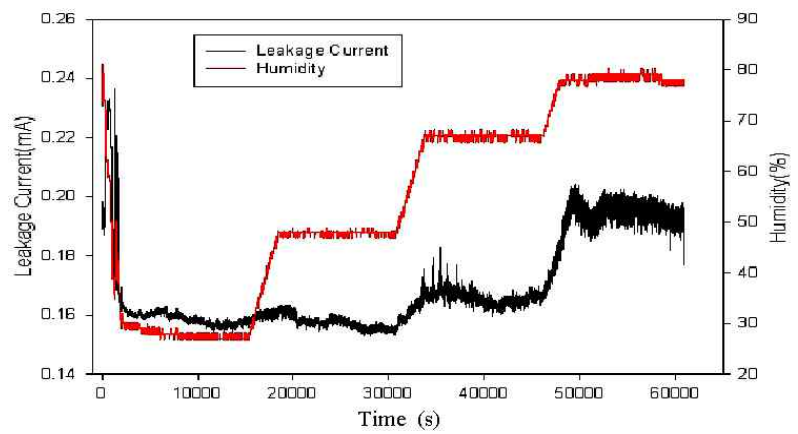

Fig. 12. Change in Leakage Current According to Humidity at $35\left[{ }^{\circ} \mathrm{C}\right]$

The leakage current increased in proportion to the increase in the humidity, and more rapidly after the relative humidity exceeded 50[\%]. Therefore, the leakage current had a close relationship to the humidity.

Figs. 13-15 show the changes in the leakage current when the temperature was $10\left[{ }^{\circ} \mathrm{C}\right], 25\left[{ }^{\circ} \mathrm{C}\right]$, and $35\left[{ }^{\circ} \mathrm{C}\right]$. The applied voltage did not significantly influence the magnitude of the leakage current.

The case at $25\left[{ }^{\circ} \mathrm{C}\right]$ especially indicates that the change in voltage does not influence the change in leakage current as much as humidity does.

The low-voltage--side current that was measured according to the humidity and the current that was measured according to temperature and the applied voltage at a constant humidity show that the current in the line has nothing to do with the temperature, humidity, or insulation performance of insulators.

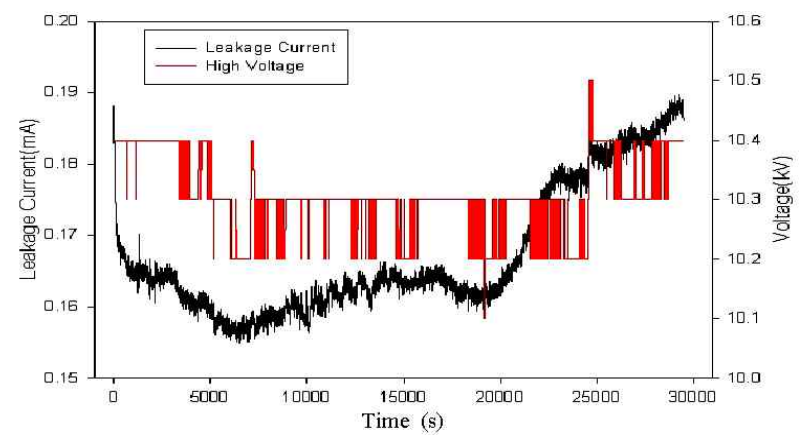

Fig. 13. Change in Leakage Current According to Voltage at $10\left[{ }^{\circ} \mathrm{C}\right]$ 


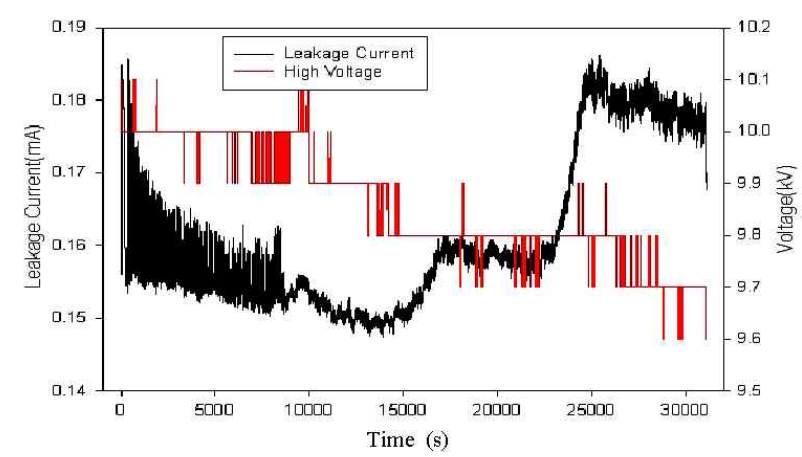

Fig. 14. Change in Leakage Current According to Voltage at $25\left[{ }^{\circ} \mathrm{C}\right]$

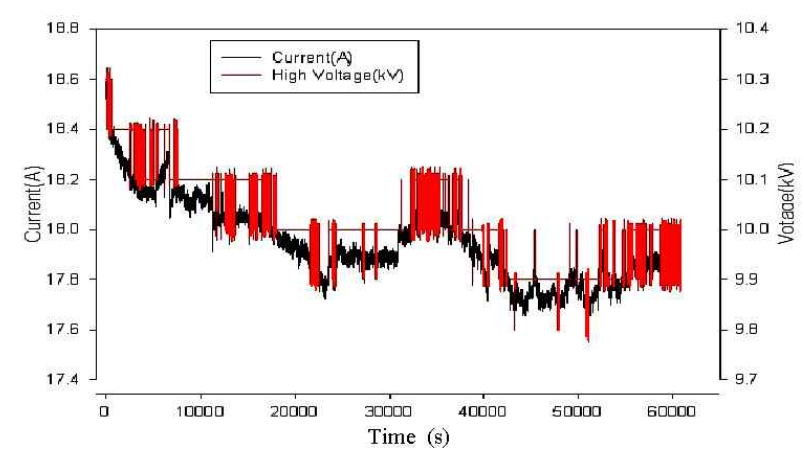

Fig. 15. Change in Leakage Current According to Voltage at $35\left[^{\circ} \mathrm{C}\right]$

The current is proportional to the voltage applied to the line. It was found that the current measurement could not be applied to the pollution level measurement.

Accordingly, the current measurement method and results cannot be used as an index for bad insulator detection and pollution measurement.

This indicates that humidity has a significant impact on the pollution of the insulator.

\section{Salt Damage Pollution}

\subsection{Experimental Method and Conditions}

As in Section 2.1, a system for a leakage current test according to humidity was prepared, and suspension insulators, $\mathrm{NaCl}$, a drier, and distilled water were added for the salt damage pollution test.

Under the same conditions as those of the leakage current test according to humidity, the salt percentage of the insulator per leakage current was estimated using the leakage current data, based on the humidity values according to the change in salt level.

This test showed that the salt level of the insulator, which is the major salt damage pollution factor, can be estimated merely by measuring the leakage current, and the time needed for insulator maintenance can be estimated.

The experiment was conducted in the same way as was the leakage current test according to humidity, except that the temperature control, which was not related to the leakage current, was limited.

This was because the leakage current hardly changed according to the change in temperature in the leakage current test according to humidity and was very sensitive to the change in humidity. For the salt pollution test, an insulator that was polluted with salt was used. The following are the additional test equipment used for the salt damage pollution test.

In this study, as in the leakage current test according to humidity, the temperature and humidity, which are among the climatic factors that influence the pollution of insulators, were controlled to measure the characteristics of the current and the leakage current according to the insulation performance of the insulator [4].

The temperature was $20\left[{ }^{\circ} \mathrm{C}\right]$, and humidity ranged from $30[\%]$ to $70[\%]$. The temperature and humidity were controlled using the thermo-hydrostat program control. The measurement was taken for 8-10 hours. The insulator was artificially polluted with salt. The humidity was raised to $0.5-1$ hour.

When the target values of humidity were reached, 
the condition was maintained for 2 hours to influence the insulation performance of the insulators. The humidity data were acquired via thermo-hydrostat program control with an oscilloscope in real time $[5,6]$.

\subsection{Salt Damage Pollution Test Results}

Fig. 16 shows the average leakage current of the unpolluted normal insulators according to the change in humidity [30[\%], 50[\%], and 70[\%]]. A $30[\%]$ humidity was maintained for about 2 hours, and the humidity increased to $50[\%]$ within $0.5^{-1}$ hour.

It also increased to $70[\%]$ within $0.5-1$ hour, and was maintained for 2 hours. Thus, the change in the leakage current according to humidity ranged from 0.04 to $0.05([\mathrm{~mA}])$.

Fig. 17 shows the leakage current of the polluted insulator $10([\mathrm{~W} \%]$ ) in the same humidity condition as that of the normal insulator in Fig. 16.

The leakage current of the polluted insulator was about 10 times that of the normal insulator, and the thermo-hydrostat provided humidities of 30[\%], 50[\%], and 70[\%]. The leakage current magnitudes of the normal insulator and the 10([W\%]) polluted insulator were compared. The leakage current of the polluted insulator rapidly increased compared to that of the normal insulator.

As shown in the leakage current in the 10 ([W\%]) humidity condition, the insulator material has recovering power, to some extent. If the deterioration is accelerated, however, the insulator material cannot be recovered.

When pollutants are deposited on the insulator surface and the pollutant layer becomes humid, the soluble conductor in the pollutant starts to melt and the leakage current increases.

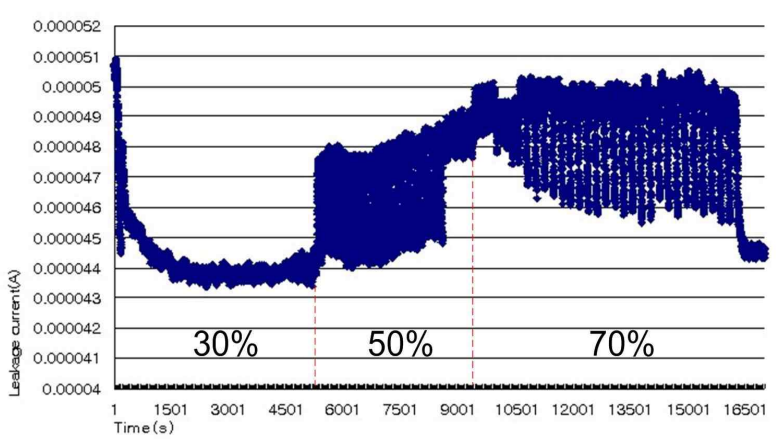

Fig. 16. Leakage Current of a Normal Insulator

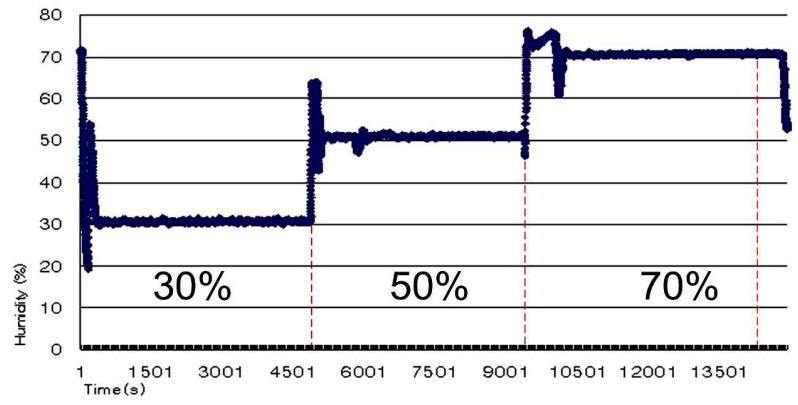

(a) Humidity

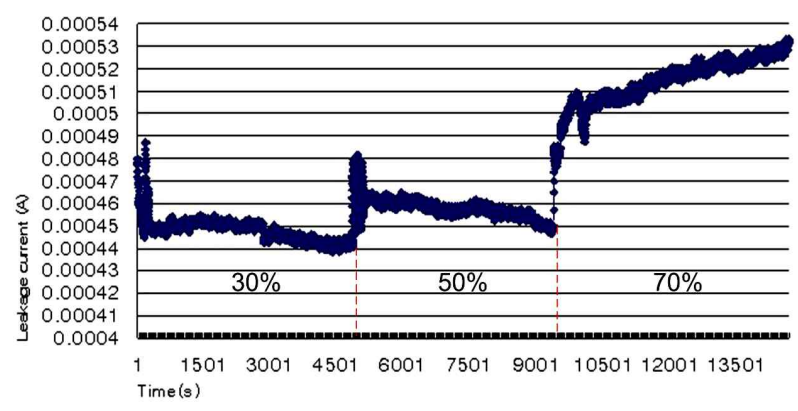

(b) Leakage Current

Fig. 17. Leakage Current According to the Humidity Condition in the Case of 10([W\%]) Salinity

If the leakage current rapidly increases on the insulator, a dry band is formed by the moisture evaporation and the original condition cannot be restored. Increasing resistance makes the voltage concentrate on the dry band. If the insulation strength exceeds that of the air, a flashover can 
occur [5].

Figs. 18-22 show the leakage current curves of the 20([W\%]), 30([W\%]), 40([W\%]), 50([W\%]), and 60([W\%]) polluted insulators, respectively. Table 2 shows the leakage current according to humidity. These graphs show that the leakage current proportionally increases with the increase in the salt damage pollution level.

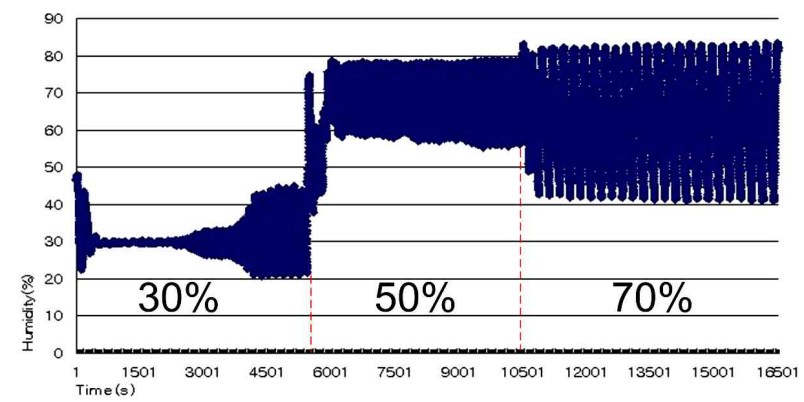

(a) Humidity

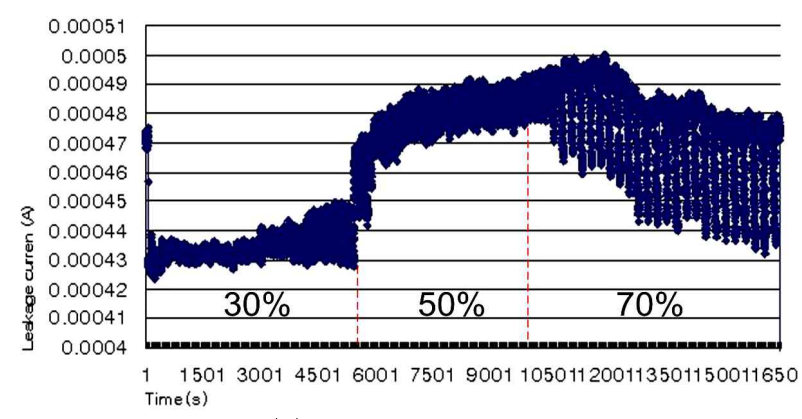

(b) Leakage Current

Fig. 18. Leakage Current According to the Humidity Condition of $20([\mathrm{~W} \%])$ Salinity

If the leakage current magnitude is identified, the salt damage pollution condition of the insulator can be identified merely by measuring the humidity and the leakage current. Using these data, the leakage current of normal and polluted insulators can be compared, and the salt pollution level can be estimated merely by measuring the leakage current of the polluted insulator.

Table 2 shows the leakage current according to the salt damage pollution level of the normal

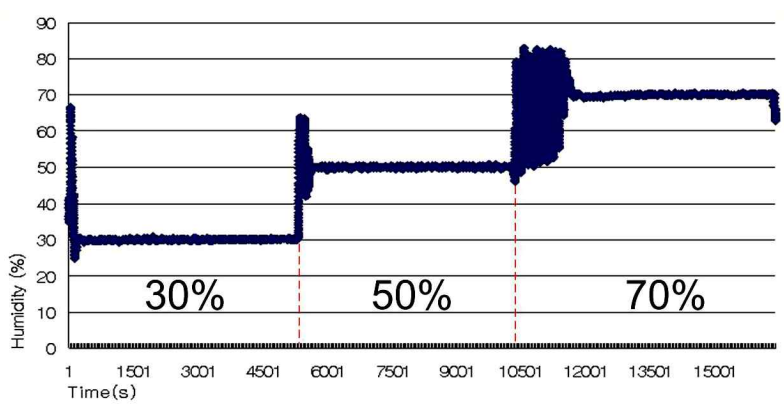

(a) Humidity

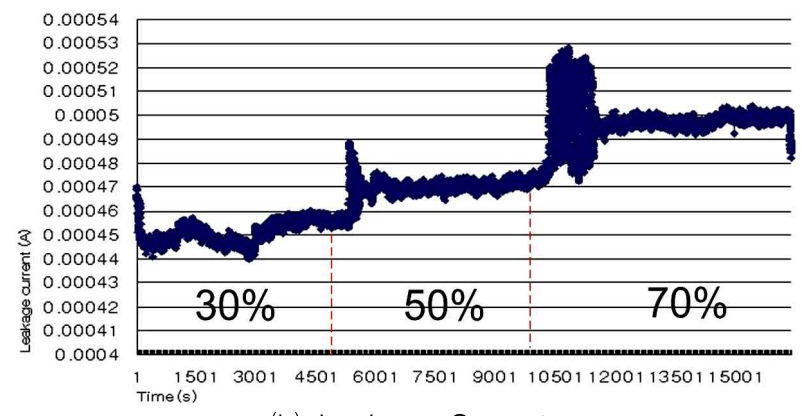

(b) Leakage Current

Fig. 19. Leakage Current According to the Humidity Condition of $30([\mathrm{~W} \%])$ Salinity

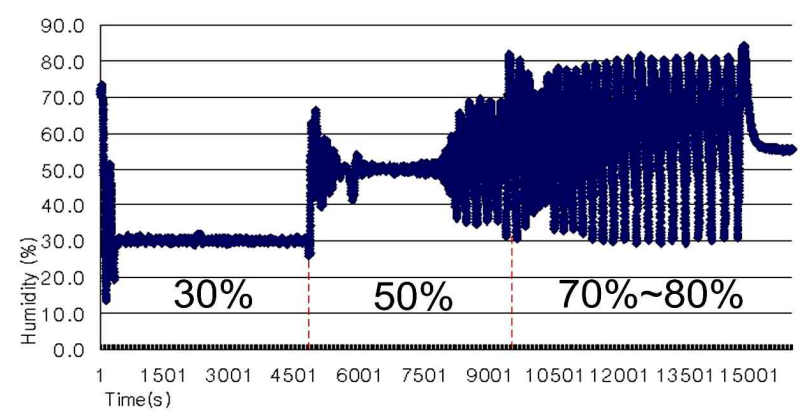

(a) Humidity

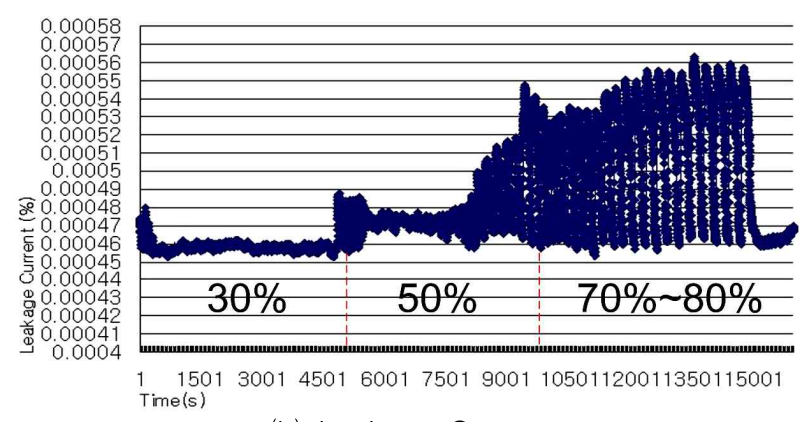

(b) Leakage Current

Fig. 20. Leakage Current According to the Humidity Condition of $40([\mathrm{~W} \%])$ Salinity 


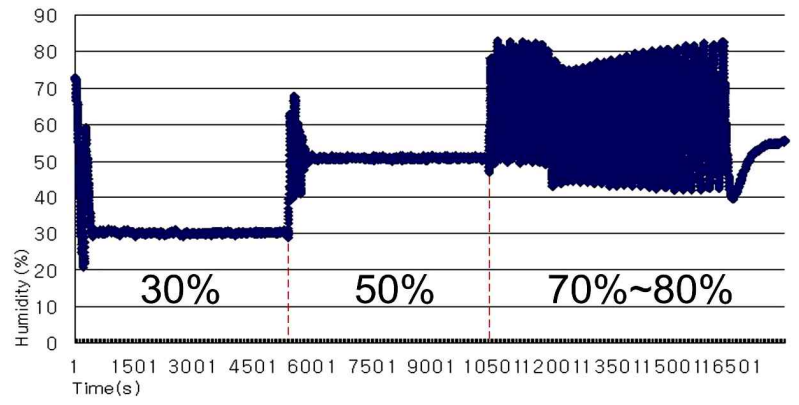

(a) Humidity

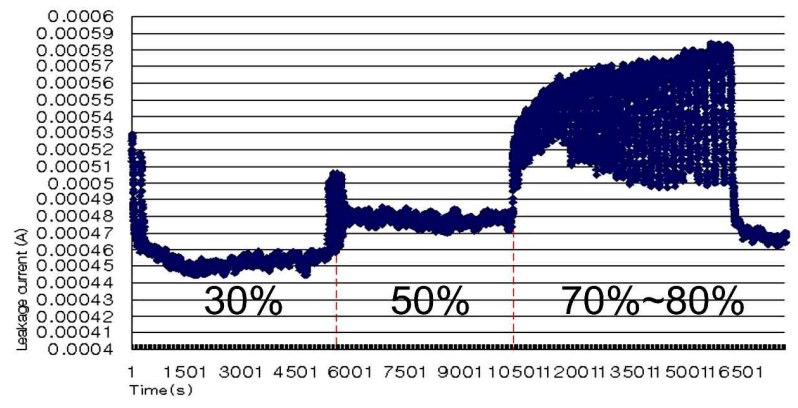

(b) Leakage Current

Fig. 21. Leakage Current According to the Humidity Condition of $50([\mathrm{~W} \%])$ Salinity

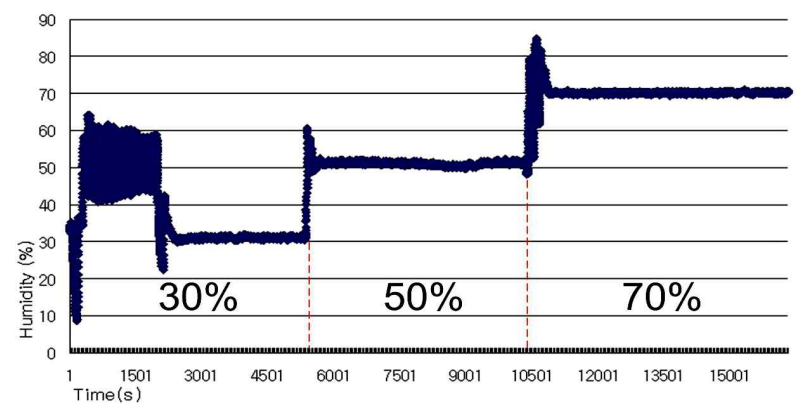

(a) Humidity

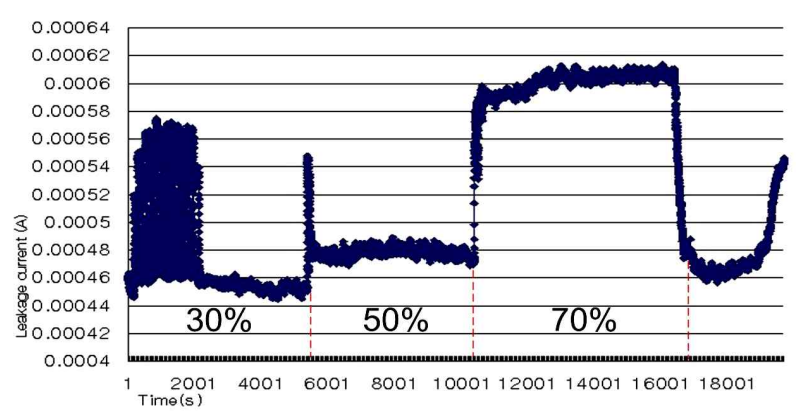

(b) Leakage Current

Fig. 22. Leakage Current according to the Humidity Condition of $60([\mathrm{~W} \%])$ Salinity insulators and the insulators that were contaminated with 10-60([W\%]) salinity. The leakage current increased with the increase in the salt damage pollution level. This shows that the salt damage pollution condition of insulators could be estimated merely by measuring the humidity and the leakage current.

Table 2. Leakage Current by Humidity

\begin{tabular}{|c|c|c|c|c|c|c|c|}
\hline Salinity & Normal & 10 & 20 & 30 & 40 & 50 & 60 \\
\cline { 3 - 8 } Humidity & Insulator & \multicolumn{6}{|c|}{$([\mathrm{W} \%])$} \\
\hline $30[\%]$ & 0.044 & 0.45 & 0.46 & 0.46 & 0.46 & 0.46 & 0.46 \\
\hline $50[\%]$ & 0.048 & 0.46 & 0.46 & 0.47 & 0.48 & 0.49 & 0.49 \\
\hline $70[\%]$ & 0.05 & 0.53 & 0.47 & 0.5 & 0.51 & 0.55 & 0.61 \\
\hline $80[\%]$ & - & - & 0.5 & 0.53 & 0.56 & 0.58 & - \\
\hline
\end{tabular}

\section{Conclusion}

In this paper, a leakage current test was conducted with reference to humidity to find the most influential factor of the pollution level of the insulator. The current at the low-voltage side, according to the applied voltage, temperature, and humidity, and the change in the leakage current according to the constant humidity were measured and compared. The leakage current was measured after it was found that it is the most sensitive factor of the insulator pollution. In terms of temperature and humidity, the leakage current significantly changed when the humidity exceeded $50[\%]$ and was not notably affected by the temperature.

There are several methods of evaluating the insulator pollution level, including current or leakage current measurement according to the changes in temperature and humidity. In this study, the leakage current measurement was used to measure the salt damage pollution level.

As identified in this study, the leakage current of 
the unpolluted normal insulator was so small that it barely existed. The leakage current of the insulator increased with the progress of the pollution, however, and it rapidly increased when humidity exceeded 50[\%]. The leakage current was also about 10 times that of the normal insulator.

After the progress of the pollution, the surface of the insulator became humid due to fog or rain, and after the partial discharge stage, it led to a flashover. Therefore, using this test, the magnitudes of the leakage current of normal insulators and salt polluted insulators can be compared.

Consequently, the salt damage pollution level of the insulator can be forecasted merely by measuring the humidity and the leakage current. Using this estimation, the insulator can be maintained based on the measured leakage current, instead of based on in-bulk replacement and washing. In addition, this study will provide the data for active maintenance by measuring the leakage current and the humidity and estimating the salinity per leakage current.

\section{References}

[1] "A Study on the Salt Pollution Level and Standards Establishment." KHPCO Technical Report, 2002.

[2] Agency for Technology and Standards. KS Standards Book. Ministry of Commerce, Industry, and Energy, 2003.

[3] "A Study on the Measures to Address Salt Contamination of Power Facilities." KFPCO Tednnical Institute Report, 1988.

[4] Hiroya Homma, "Comparison of Leakage Current Properties between Polymeric Insulators and Porcelain Insulators under Salt Polluted Conditions." Proceedings of 2005 International Symposium on Electrical Insulating Materials, P 1-14, pp. 348-351, June 5-9, 2005.

[5] G. H. Vaillancourt, J.P. Bellerive, M. St-Jean, and C. Jean. "New Live Line Tester for Porcelain Suspension Insulators on High-voltage Power Lines." IEF Transactions on Power Delivery, Vol. 9, No. 1, pp. 208-219, January 1994.

[6] T.J. Gallagher, A.J. Pearmain, "High-voltage Measurement, Testing, and Design." John Wiley \& Sons, pp. 209-212, 1983.

\section{Biography}

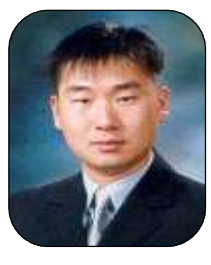

Dae-Dong Lee

Born December 26, 1976.

B.S. Electronic Engineering, Woosong University in 2002.

M.S. Electrical Engineering, Graduate School of Hanbat National University in 2004.

Ph.D. Course in Electrical Engineering, Graduate School of Hanyang University (2007-present).

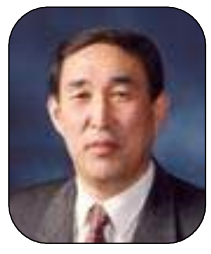

Dong-Seok Hyun

Born April 8, 1950

B.S. Electrical Engineering, Hanyang University in 1973.

M.S. Electrical Engineering, Graduate School of Hanyang University in 1978. Ph.D. in Electrical Engineering, Graduate School of Seoul National University in 1986. Exchange Professor, Toredo University, USA, 1984-1985. Exchange Professor, Technical University of Munich, 1988-1989. Fellow Member of IEEE in 2003. Professor, Division of Electrical and Biomedical Engineering, Hanyang University (1979-present).

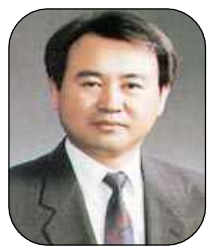

Young-Dal Kim

Born November 5, 1957.

B.S. Electrical Engineering, Daejeon Technology College in 1986. M.S. Electrical Engineering, Graduate School of Chungbuk University in 1990 . Ph.D. in Electrical Engineering, Graduate School of Myongji University in 1999. Professor, Department of Electrical Engineering, Hanbat National University. His Research Areas are Active Noise Control \& Vibration for Power Transformers, and Conversion System for Wind Force. 